\title{
Working
}

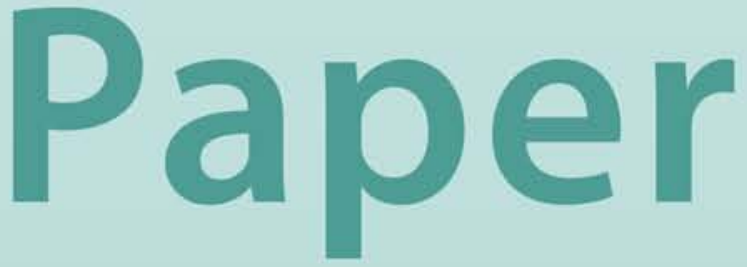




\section{Poverty and Social Impact Analysis: \\ A Suggested Framework}

Shahabuddin M. Hossain 


\title{
IMF Working Paper
}

\author{
African Department \\ Poverty and Social Impact Analysis: A Suggested Framework
}

Prepared by Shahabuddin M. Hossain ${ }^{1}$

Authorized for distribution by Robert Sharer

October 2003

\begin{abstract}
The views expressed in this Working Paper are those of the author(s) and do not necessarily represent those of the IMF or IMF policy. Working Papers describe research in progress by the author(s) and are published to elicit comments and to further debate.
\end{abstract}

Following the adoption by the international community of the Poverty Reduction Strategy Paper (PRSP) approach, which provides the basis for concessional lending by the multilateral institutions, there has been a resurgence of interest in the poverty and social impact analysis (PSIA) of different policy reforms being considered by the low income countries. This paper reviews some of the major techniques and frameworks for assessing the PSIA. It highlights their strengths and weaknesses and suggests a relatively simple analytical framework for the PSIA based on household survey data. The paper then shows how the suggested framework could be utilized to investigate the poverty/income distributional implications of introducing a value-added tax (VAT). The results indicate that a revenue-neutral uniform VAT is regressive in its impact on different households. In order to mitigate the adverse impact, the paper explores the distributional impact of an alternative policy package consisting of a basic rate of VAT with exemptions and excise taxes for certain commodity groups chosen on the basis of their distributional characteristics. The distributional consequences of the alternative package are found to be superior to those of the uniform VAT.

Keywords: Poverty and social impact analysis, incidence analysis, computable general-equilibrium models, equivalent variation, effective taxes, linear expenditure system, value-added tax.

Author's E-Mail Address: shossain@imf.org

JEL Classification Numbers: D12, D58, D60, H22

\footnotetext{
${ }^{1}$ The author is grateful to Jean Clément, Dhaneshwar Ghura, Caroline Kende-Robb, Bernardin Akitoby, Milan Cuc, Benoît Mercereau, and participants in an IMF African Department seminar for their useful suggestions and comments. In addition, the author also benefited from comments provided by Jeffrey Davis and Kevin Fletcher (FAD) and discussions with Shantayanan Devarajan, Delfin Go, and Martin Ravallion (World Bank) on analytical issues.
} 


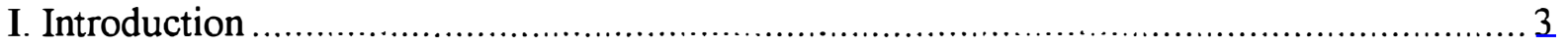

II. Framework for Poverty and Social Impact Analysis: An Analytical Review .................. 3

III. Poverty and Social Impact Analysis: A Suggested Framework .................................. I

A. Impact of Reform on Prices of Goods ................................................ 8

B. Capturing the Demand Response: Linear Expenditure System ....................... 9

IV. Distributional Impact of Tax Reform: An Empirical Exercise ............................... 10

A. Modeling the Reform Measure: Introduction of a Value-Added Tax (VAT) ....... 10

B. Nominal and Effective Taxes of Commodities ......................................... $\mathrm{U}$

C. Estimation of a Modified Linear Expenditure System (LES) ........................ 13

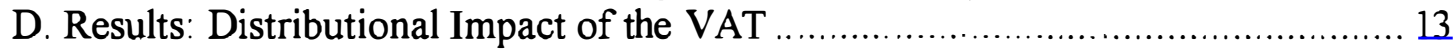

E. An Alternative Reform Package ............................................................. 15

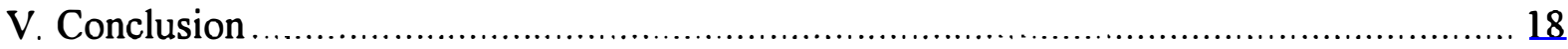

Tables

Table 1A. Revenue Shares, Budget Shares, and Taxes on Commodities ......................... 12

Table 1B. Budget Shares, Expenditure and Price Elasticities of Commodities ................ 12

Table 2. Equivalent Variation $\left(E_{o l}{ }^{h}\right)$ for Uniform VAT ..................................... 14

Table 3. Equivalent Variation $\left(\mathrm{E}_{\mathrm{ol}}{ }^{\mathrm{h}}\right)$ for Uniform VAT with Zero-Rated Commodities and Excise Taxes ......................................................................... 17

Annex

I. Simple Analytics of the Indirect Utility Function and the Expenditure Function.............20

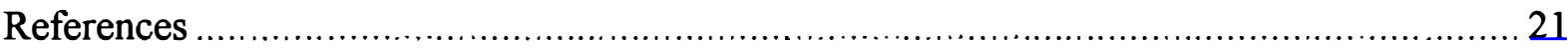




\section{INTRODUCTION}

Following the adoption by the international community of the poverty reduction strategy paper (PRSP) approach, which provides the basis for concessional lending to low-income countries from the IMF and the World Bank, there has been a resurgence of interest in the poverty and social impact analysis (PSIA) of different policy reforms facing the countries. The poverty focus of the PRSP approach, among other things, calls for undertaking a PSIA of discrete policy interventions to assess the impact on different income or social groups. A recent survey indicates that PSIAs based on rigorous analytical studies were attempted in only 34 percent of PRGF-supported countries (Inchauste, 2002). However, even in the countries employing the analytical studies, the PSIA was typically undertaken for one measure, thus leaving out a host of macroeconomic and other policy measures implemented as part of the PRGF-supported programs. These early experiences suggest that there is an analysis gap - that is, policies are being formulated and implemented without adequate PSIA (Kende-Robb, 2003). This gap partly reflects the lack of an appropriate tool or analytical framework that can be readily used by the country authorities or economists in lending organizations with the available data.

This paper discusses some of the major techniques or analytical frameworks for assessing the PSIA of policy reforms, highlighting their strengths and weaknesses (Section II). It then suggests a relatively simple analytical framework, based on household expenditure surveys, that could be utilized to assess the income-distributional impact of a discrete intervention policy on different income groups in urban and rural areas (Section III). Based on an earlier study by the author, the paper also provides an illustration of how the impact of a major tax reform (for example, introduction of a value-added tax) on different urban and rural groups can be analyzed (Section IV). To mitigate the adverse distributional impact of the initial tax reform, the study also identifies a modified reform package that is beneficial or least damaging to poor households. The conclusion of the paper is presented in Section V.

\section{Framework For Poverty and Social Impact ANalysis: AN ANALYTICAL REVIEW}

PRGF-supported programs in low-income countries typically involve policy reforms or changes in the area of taxation and expenditure policy, trade and exchange rate policy, deregulation of domestic prices, civil service reforms, wage policy, privatization, and other reforms. While many of these reforms are aimed at reducing fiscal deficits, improving macroeconomic stability, and enhancing economic efficiency, many of the measures affect different income and social groups differently and may hurt or benefit the poor, vulnerable and low-income groups more. Given the poverty reduction goal of the PRSP, policymakers need to know this distributional impact to assess the desirability or feasibility of a policy change, as well as to address the possible adverse poverty/income distributional impact through alternative policy instruments. 
It is possible to identify a number of broad techniques or frameworks for analyzing the impact of policy changes on different socioeconomic groups. Policy changes can be assessed both ex ante or ex post. One broad approach that has been in use for quite some time is called incidence analysis. Incidence analysis has been carried out for many countries and in most cases focuses on impact of changes in tax and public spending policy on household income or welfare, often using econometric techniques. It makes intensive use of household survey data to evaluate policies in terms of their effect on particular households groups - by income/ expenditure, region, education, gender, etc. The starting point of such an analysis is the household data, which provide information on how much of different commodities each household group consumes and on each groups' source of income. The incidence analysis measures the deadweight loss/gain of changes in taxation for each household group, given its consumption patterns. ${ }^{2}$ In case of public expenditure programs, incidence analysis measures the welfare gains for each household resulting from direct transfers or the provision of public goods/services, or through a reduction in the price of goods/services (e.g., education or health programs). The analysis is useful because it can trace the impact of the policy change on the income levels of different household groups (classified by income/expenditure, region, or other social characteristics); this enables policymakers to assess the desirability or feasibility of the policy change, as well as to design compensation schemes to deal with potential adverse consequences. However, there are a number of weaknesses in incidence analysis. First, conventional incidence analysis focuses on the direct and immediate impact on households, leaving out the behavioral response of households to the policy reforms. The behavioral response is important for two reasons. First, because individuals or households are likely to consume smaller (larger) amounts of a commodity whose prices have gone up (down) as a result of the reform. Second, an individual may decide to work less if that person receives income transfers from the public agencies. As noted below, more sophisticated empirical models also take account of the behavioral response of households to the policy reforms. Another weakness is that, by its construct, incidence analysis ignores the impact on the production side of the economy and cannot address the general equilibrium implications of policy change in the economy. While some new-generation models can look at the impact of tax and price changes in one sector on the prices of other commodities, the production side of the economy is usually kept in the background.

An alternative approach that brings the production side into the analysis and can be used to assess the impact of a policy reform on a developing country is a framework based on the computable general equilibrium (CGE) model. ${ }^{3}$ A CGE model incorporates the fundamental general equilibrium links among productions structures, incomes of various groups, and the

${ }^{2}$ Typically, data show that, for low-income household groups, food and other necessities make up a larger share of expenditure than high-income households. Conversely, luxury goods make up a larger share of high-income households' expenditure relative to low-income households. A change in commodity taxes affects the household groups positively if the tax rate declines, or negatively if the tax rate rises.

${ }^{3}$ Among others, Shoven and Whalley (1984) and Dervis and others (1982) provided a comprehensive analytical review of the CGE models. 
pattern of demand; it is capable of tracing large changes in a particular policy throughout the entire economy. The distinguishing feature of this class of model is price endogeneity, even though limited nonprice adjustment mechanisms can also be built into the model. The theoretical basis of the CGE model is the Walrasian general equilibrium theory. Long-period conceptual innovation and refinement, combined with the development of computing facilities, made the general equilibrium model operational. In a typical CGE model, each agent (or group of agents) have their demand functions, given the prices of goods and factors and subject to budget (income) constraint. The main strength of this approach lies in its ability to provide a framework where prices are endogenously determined and that plays a key role in the allocation and distribution mechanisms. It also affords a very flexible treatment of the production and demand side of the economy by allowing substitution possibilities. Thus, it permits an explicit treatment of income distributional problems through the operation of product and factor markets in an interdependent system of supply and demand.

A strong assumption in the CGE model is the idea that markets for goods and factors clear and determine the relative prices ruling in equilibrium. In developing countries, prices of many goods and factors are fixed exogenously (or have a very limited degree of flexibility), whether (i) because of government control, or (ii) parametrically, given world prices and tariffs or (iii) due to market imperfections. CGE models can handle price rigidity, without compromising the basic principle of equilibrium only in limited markets. Whenever price rigidity leads to unemployment in the labor market or excess demand in the goods market, the common practice in CGE models is to opt for a mechanism whereby quantity-constrained agents receive employment or goods in proportion to their share in the total supply of labor or demand for goods. The implicit rationing procedure seem to have no compelling analytical justification. Another basic underlying assumption in the CGE model is the assumption of perfect competition that governs the structure of the market for commodities and factors. Extending the model to incorporate noncompetitive behavior is extremely difficult. When CGE modelers do not assume perfect competition, their standard practice is to resort to some sort of markup pricing rule in which the markup is usually exogenously fixed, without any clear rationale for the magnitude and nature of specification. Another feature of most, if not all, CGE models is that only relative prices matter-in other words, the models are homogeneous of degree zero in prices, and absolute prices are of no consequence. In reality, however, inflation plays an important role both in developing and developed countries.

In spite of its many attractive features, some critical aspects of the CGE model make it difficult and often inappropriate to use a CGE model for PSIA in developing countries. First, its data requirement are highly demanding, making it time-consuming and difficult to develop. In CGE models, the parameter values for the functions are often crucial in generating the qualitative results of policy simulations. The procedure most commonly used to estimate parameters is called calibration (typically done using a benchmark year's data). While econometric work often simplifies the structure of the economic models so as to allow substantial richness in statistical specification, here the procedure is quite the opposite. The richness of the economic structure only allows for the use of much cruder statistical methods, which, in the case of calibration to a single year's data, becomes deterministic. Second, at the analytical level, insofar as a CGE model is an inadequate description of economic structure 
and behavior in a low-income, developing country, formal policy analysis based on such a model could be misleading. In many developing countries, there are numerous market imperfections and distortions, some of which are policy induced. In such cases, imposing perfect competition and market-clearing assumptions are inappropriate and may generate misleading results. Third, in a CGE framework, it is often difficult to see whether the result of a policy simulation is due to specific behavioral or structural assumptions or stems from the degree of disaggregation and substitution possibilities in the economy. Bell and Srinivasan (1984) argue that the qualitative behavior of the economy (as a static system) in CGE models stems not so much from the extent of disaggregation or the possibilities of substitution as from the manner in which "closure rules" is specified, meaning the way in which investment and savings (or, more generally, supplies and demands) are brought into equality.

Notwithstanding these restrictive features, there are some circumstances when CGE models may be appropriate to capture the critical economy-wide impact of macroeconomic policies and shocks that directly affect the relative product and factor prices and thus income distribution even in the short run. Examples of such macroeconomic shocks and policies include, large changes in terms of trade, or large scale trade reforms. In recent years, attempts have been made to simplify the CGE modeling framework and make it less demanding in terms of data requirement. One such attempt is the construction of a 123 PRSP model by Devarajan and Go (2002). It is a highly aggregative two-sector, but multihousehold model, with two somewhat disjoint modules that can capture the short-run effects of macroeconomic policies and shocks on relative prices and wages, as well as the effects of policies on growth through an extraneous growth equation. The model has been applied to analyze the impact of external shocks (changes in external terms of trade) and macroeconomic policies and (change in aggregate public expenditures) on income distribution (across ten deciles or income groups). The model has the attractive features that it is simple, is not informationally demanding and is capable of identifying some tradeoffs in poverty reducing macroeconomic policies. However, because of its aggregative nature (only two sectors on the production side) it is not suitable to investigate the impact of a wide range of sectoral policy changes (e.g., changes in commodity taxes and prices, changes in public expenditure on education and health, etc.). Extraneous "closure rules" continue to play a critical role in generating the qualitative results.

In wide range of cases where CGE models are considered very restrictive in their representation of a developing country and informationally very demanding, one could argue that alternative approaches that do not attempt to model the entire economy could be more appropriate where the focus of policy reform is more limited, i.e., restricted to the poverty and social impact of policy reform on different income and social groups in the economy. An alternative approach in the tradition of incidence analysis, originally put forward by Ahmad and Stern (1987), also uses detailed household expenditure survey (HES) data to identify winners and losers of a policy reform in a population characterized by income inequality. However, this approach overcomes a major weakness of the static incidence analysis by incorporating behavioral demand response, as well as the impact of a tax/price change in one sector or others. Under this approach, the welfare impact of a policy reform, say, tax reform is evaluated by specifying an estimated demand/supply response, as well as an associated 
indirect utility function. It uses an exact money measure of welfare change, namely, "equivalent" or "compensating" variation. This approach also enables one to evaluate the impact of a discrete policy change by looking at the trade-off between achieving a certain policy goal (e.g., revenue gain/loss), on the one hand, and welfare loss/gain, on the other. ${ }^{4}$ Policymakers may find the information provided by this approach very useful and easy to follow; however, in comparison with the CGE modeling approach, this approach uses detailed data on the household and welfare side, while the production side of the economy is kept in the background (Stern (1987b)). The basic elements of the Ahmad and Stern (1987) method are discussed below.

\section{Poverty aNd Social ImPaCt ANALysis: A SUggested FrameWORK}

The basic concept underlying the framework is straightforward. It is assumed that, in the short run, economic policy change in the economy affects the income levels of different income/social groups mainly through changes in prices of commodities they consume or income transfers (cash or kind). In addition, changes in factor prices can also affect different groups in proportion to their factor endowment. Pre- and post-reform vectors of consumer prices are denoted by $q^{0}$ and $q^{1}$, while the measures of pre- and post-reform social welfare can similarly be represented by $\mathrm{W}^{\circ}, \mathrm{W}^{1} .{ }^{5}$ To avoid any reference to the controversial social welfare function, it is possible to calculate the indirect utility levels using the expenditure function approach corresponding to pre- and post-reform situations, namely, $\mathrm{V}^{\text {ho }}$ and $\mathrm{V}^{\mathrm{hl}}$ for each household (or household group), and thus assess the positive or negative impact of policy reform on each household. The utility change for household $\mathrm{h}$ or $\left(\mathrm{V}^{\mathrm{hl}}-\mathrm{V}^{\mathrm{ho}}\right)$ can be expressed by the "equivalent variation" measure, which is defined by the following implicit equation:

$$
V^{h l}=V^{h}\left(q^{o}, M^{\text {ho }}+E_{o l}^{h}\right)
$$

Here, $M^{\text {ho }}$ is the pre-reform income of the household $h$. Thus, $E_{o 1}{ }^{h}$ is simply the amount of money that needs to be given to household $h$, if the pre-reform prices were ruling, to allow it to reach the post-reform utility level. $\mathrm{E}_{\mathrm{ol}}{ }^{\mathrm{h}}$ can also be defined making use of the explicit expenditure function $\mathrm{e}^{\mathrm{h}}\left(\mathrm{q}, \mathrm{U}^{\mathrm{h}}\right){ }^{6}$

$$
E_{o l}^{h}=e^{h}\left(q^{o}, V^{h 1}\right)-M^{h o}
$$

\footnotetext{
${ }^{4}$ Attempts have also been made to produce hybrid models combining the features of both the CGE models and second generation welfare focused models based on equivalent variations. A case in point is the PAMS (Poverty Analysis Macroeconomic Simulator) framework presented by Bourguignon and Pereira da Silva (2002).

${ }^{5}$ One way to approach the problem is to identify changes from $t^{\mathrm{eo}}$ to $\mathrm{t}^{\mathrm{e} 1}$ that yield $\mathrm{W}^{1}>\mathrm{W}^{\mathrm{o}}$ and $\mathbf{R}^{1} \geq \mathbf{R}^{\circ}$ (i.e., post-tax revenue should be at least as high as the pre-tax revenue).

${ }^{6}$ For illustration of the basic concepts and welfare measures, see Annex I.
} 
Thus, $E_{01}{ }^{b}$ is a money measure of the benefit (loss) of the reform to household $h$. It is positive for a utility gain and negative for a utility loss. ${ }^{7}$ The measure is a relatively simple but robust tool to analyze the income distributional impact of a nonmarginal or discrete policy reforms. Two major steps are necessary to translate this measure into an empirical tool: first, to assess the impact of policy change on prices of commodities/factors (and direct transfers, if any); and second, to utilize the set of prices to assess the impact on household income by using an equivalent measure that takes into account the demand response of changes in prices. The latter step is facilitated by an explicit specification of consumer preferences. One such specification widely used in low-income countries and that is relatively easy to estimate is linear expenditure system (LES).

\section{A. Impact of Reform on Prices of Goods}

As noted above, the first task of the exercise was to assess the impact of reform on the prices of final goods. For simplicity, we assume that the reform takes the form of an imposition of indirect taxes (subsidies) that affects the prices of one good directly. In empirical analysis, it is customary to assume that changes in indirect taxes are passed to the consumers or users through changes in prices of the product. Among others, Stern (1987b) has studied the effect of taxes in noncompetitive models. He concludes that 100 percent tax shifting, as assumed in the conventional model, is a reasonable intermediate case valid in a wide range of market conditions and not an extreme or polar case, as is often implied. Even if the price of the commodity subject to additional taxes (or subsidies) can be determined, conventional analysis ignore its impact on other commodities. While this underlying assumption is valid for some commodities, often prices of one commodity affect other prices in the economy in a significant way. A case in point is the prices of petroleum products and utilities, which are widely used in any economy, both as inputs and as items for final consumption. Thus, it is necessary to assess the impact of a tax/price change in one sector on the prices in other sectors. To do that, one can make the standard assumption that the tax element in the final consumer prices is defined by "effective" taxes that capture the cascading effect of all input taxes in the economy, so that $t^{\mathrm{e}}=\mathrm{t}^{\prime}(\mathbf{I}-\mathbf{A})^{-1}$, where $\mathrm{t}^{\mathrm{e}}$ and $\mathrm{t}^{\prime}$ are, respectively, effective and nominal tax vectors, $\mathbf{A}$ is input-output flow matrix, and $\mathbf{I}$ is an identity matrix. Typically, a change in $t$ in sector I would affect $t$ in all other sectors through the input-output relationship. Given the fixed producer price vector, $\mathbf{p}$, the final consumer price vector is given by

\footnotetext{
${ }^{7}$ It is argued that the use of an "equivalent variation" measure has one distinct advantage over an alternative measure of exact welfare change, namely, "compensating variation" (defined as the amount of money that the household would need to be given at post-reform prices in order to attain the pre-reform level of utility). It relates to the use of a reference price vector to evaluate the reforms. Measures based on "compensating variation" use postreform price vector as a reference point implying the use of a different reference price vector for each reform. Thus, the money value of gain/loss from reform A cannot be compared with the money value of a gain/loss from reform B. Measures based on "equivalent variation" are free from the analytical problem because a pre-reform price vector is used to evaluate all possible reforms (King, 1983).
} 


$$
\mathbf{q}=\mathbf{p}+\mathbf{t}^{\mathbf{e}}, \quad \text { where } \mathrm{t}^{\mathrm{e}}=\mathbf{t}^{\prime}(\mathbf{I}-\mathbf{A})^{-1}
$$

This framework can be used to assess the impact of not only indirect taxes and subsidies but also of a wide range of reform measures that affect the prices of goods and services. Examples of some reforms are changes in indirect taxes and subsidies, a change in the VAT rate, and a change in administered prices of products (petroleum products, utility rates, prices of education and health, etc.). As long as the direct impact of the reform measure on the prices of goods and services can be identified, the impact on prices on other goods and services in the economy can be traced, making use of the framework.

\section{B. Capturing the Demand Response: Linear Expenditure System}

Under a LES specification of consumer preference, household demand for a commodity has two components: a "minimum" consumption requirement of a commodity, which is independent of household income, and a variable component, which depends on household income. Following is a standard specification of the LES:

$$
X_{i}=\gamma_{i}+b_{i}\left(M-\Sigma \gamma_{j}\right) \quad i=1, \ldots \ldots, n ; \quad \text { where } \Sigma b_{i}=1 \text {, }
$$

where $\mathrm{X}_{\mathrm{i}}$ is the expenditure on ith good, $\mathrm{M}$ is the total expenditure in monetary terms, $\gamma_{\mathrm{i}}$ is the value of "minimum" consumption expenditure on the ith commodity, and $\left(\mathrm{M}-\Sigma \gamma_{\mathrm{j}}\right.$ ) is the additional consumption expenditure. The $\mathrm{b}_{\mathrm{i}}$ are often referred to as the "marginal budget shares". The parameters of the LES for each household group can be estimated with data on $\mathrm{Xi}$ (expenditure on commodity $\mathrm{i}$ ) and $\mathrm{M}$ (total expenditure on all commodities), which are available in all household survey data. However, the demand system as specified in (4) is underidentified. This is clear by looking at the reduced form:

$$
X_{i}=a_{i}+b_{i} M \quad i=1, \ldots \ldots, n .
$$

The adding-up constraint $\Sigma X_{i}=M$, which holds for all households, implies that $\Sigma a_{i}=1$ and $\Sigma b_{i}=1$. The reduced form would provide us with $2 n-2$ independent parameters among $a_{i}$ and $b_{i}$, from which we need to construct $2 n-1$ parameters in the structure ( $n$ of $\gamma_{i}$ and n-1 independent $b_{i}$ ). The standard way of achieving identification in this context is to set one of the $\gamma_{i}$ to zero. One can also introduce an alternative but more appealing formulation by making some $\gamma_{\mathrm{i}}$ (minimum consumption) depend on household size, leaving others to be determined exogenously. If we assume that consumer preferences are represented by a modified LES as described above, then the equivalent variation in equation (2) could be expressed in terms of

$$
E_{o l}{ }^{h}=\left(M^{h}-q^{1} \cdot a\right) \Pi_{i}\left(q_{i}^{o} / q_{i}^{1}\right)^{b i}-\left(M^{h}-q^{o} \cdot a\right)
$$

where $\mathrm{M}^{\mathrm{h}}$ is the per capita expenditure level of household group $\mathrm{h}$, the $\mathrm{q}^{0}$ and $\mathrm{q}^{1}$ are the preand post-reform prices, and " $b_{i}$ " is the marginal budget share of commodity group $i$, which, along with "a" (constant), is determined by the modified LES estimated for each household group. 
The basic framework outlined above can be used to assess the income distributional impact of a wide range of policy reforms: a change in the direct or indirect tax rates, the introduction of a value-added tax (VAT), a change in the administered prices of products (food and petroleum products) or subsidy schemes, a change in government expenditure that directly affects the households (education, health, and other social expenditures), trade policy reforms affecting the levels and dispersion of tariffs, and exchange rate adjustments.

\section{DISTRIBUTIONAL IMPACT OF TAX REFORM: AN EMPIRICAL EXERCISE}

This framework has been used in the Bangladesh context to assess the impact of nonmarginal tax reforms, namely, introducing a specific VAT scheme (Hossain, 1995). Before the introduction of a VAT in 1991, there were three basic categories of indirect taxes in Bangladesh: excise taxes, import duties, and the sales tax. The excise taxes were collected entirely on domestic production, import duties were collected on imports, and a sales tax was imposed on both domestic sales and imports. There are a number of VAT schemes one could consider: (i) a completely uniform VAT applied to all goods (defined to include services); (iii) a nonuniform VAT, with different rates applied to different commodities; and (iii) a VAT at a uniform rate but applying only to a subset of goods and zero rating (and/or exemption) for other goods (and possibly some supplementary excise taxes that can go with the VAT). This latter scheme resembles the Bangladesh case. Here, for the present purpose, uniform VAT is simply defined as a tax system that makes the proportion of effective tax in the price of final goods uniform (same) for all goods. ${ }^{8}$

\section{A. Modeling the Reform Measure: Introduction of a Value-Added Tax (VAT)}

The tax reform associated with the introduction of a VAT envisages replacing the existing indirect taxes with a uniform (or nonuniform) VAT rate that is broadly revenue neutral. If the VAT rate is uniform at the level "r," then it implies that

$$
\mathrm{r}=\mathrm{t}_{\mathrm{i}}^{\mathrm{el}} / \mathrm{q}_{\mathrm{i}}^{\mathrm{l}}
$$

for all $\mathrm{i}$. The rate " $\mathrm{r}$ " will be determined by the government's revenue requirement. Thus, if $\mathrm{R}^{1}$

is the amount of revenue that need be raised from total consumer expenditure, then

$$
\mathrm{r} \Sigma_{\mathrm{i}} \mathrm{q}_{\mathrm{i}}^{1} \mathrm{X}_{\mathrm{i}}^{1}=\mathrm{R}^{1}
$$

\footnotetext{
${ }^{8}$ In this paper, the term effective tax has been used to denote a tax that captures the cascading effects of all input taxes in the economy. It is distinct from the nominal tax, which is the actual tax element in the purchaser's price of good $\mathrm{i}$ (in some literature, this is often referred to as the "effective" tax) or the statutory tax, which refers to legally binding tax rates imposed by taxing authorities.
} 
For fixed revenue, $\mathrm{R}^{1}=\mathrm{R}^{\mathrm{o}}$. If one assumes total consumer expenditure is unchanged by the reform, then revenue neutral " $r$ " may be simply calculated by dividing by the total pre-reform consumer expenditure. ${ }^{9}$

\section{B. Nominal and Effective Taxes of Commodities}

As the first step of the empirical exercise, the "nominal" and "effective" tax rates for 15 commodity groups ( 9 food items and 6 nonfood items) were computed using the base-year data. This required the aggregation of commodity taxes into 15 commodity groups. The choice of the commodity classification was governed by the purpose of the exercise (e.g., the level of disaggregation required for meaningful characterization of policy reform) and with a view to facilitating the estimation of a complete demand system, namely, the modified LES for different household groups, based on household expenditure survey data for Bangladesh. Table 1.A presents the nominal and effective taxes for the 15 commodity groups, along with their shares in household budget and indirect tax revenue. As noted above the effective taxes capture the cascading effects of taxes on inputs, of taxes on inputs into those inputs, and so on, and are higher than the nominal taxes. The divergence between nominal and effective tax rates often measures the unintended consequences of government policy.

The next step of the empirical exercise was to estimate the net indirect tax element in the total consumer expenditure. For Bangladesh, it was found that the net indirect tax revenue averaged approximately 5.6 percent of total consumer expenditure for the year 1984/85. Thus, the first tax reform option examined here is replacing all taxes with a uniform (proportional) VAT of approximately 5.6 percent of the tax-inclusive prices of all goods. Since this is a sizable reform package, one would expect substantial changes in consumption demand. However, as the impact of a uniform (proportional) tax on revenue from all expenditures is being examined here, it is reasonable to assume that, if total expenditure is unchanged, then the given VAT will raise the required revenue.

Given the target, revenue-neutral VAT rate, the task is to estimate the equivalent variation $\mathrm{E}_{\mathrm{ol}}{ }^{\mathrm{h}}$, defined for each per capita expenditure group (with an expenditure pattern generated by LES) presented in equation (5). The parameters " $b_{i}$ " and "a" have been derived from the econometric estimation of the LES demand systems 15 commodity groups, corresponding to 6 urban and 6 rural household groups, using the detailed household expenditure survey data. What follows is a brief discussion of the development of the database and an estimation of the LES.

\footnotetext{
${ }^{9}$ This may be a limiting assumption. However, in practice, the revenue-neutral VAT rate was calculated iteratively from the relationship $\mathbf{t}^{\mathrm{e}^{\prime}} \cdot \mathbf{X}=\mathbf{r}^{\mathrm{v}^{\prime}} \cdot \mathbf{X}=\mathrm{R}$, where $\mathbf{X}$ is the vector of aggregate consumption expenditure in the pre-reform period, $\mathbf{t}^{\mathrm{e}^{\prime}}$ is the vector of pre-reform effective taxes, and $\mathbf{r}^{\mathbf{v}^{\prime}}$ is the vector of revenue-neutral VAT rates chosen such that it satisfies the above equality. It has been found that the resulting rate/rates derived iteratively are indeed quite close to the average rate found by dividing by total consumption expenditure.
} 
Table 1A. Revenue Shares, Budget Shares, and Taxes on Commodities (in percent)

\begin{tabular}{|c|c|c|c|c|c|c|}
\hline No. & Commodity Groups & $\begin{array}{c}\text { Nominal } \\
\text { Tax }\end{array}$ & $\begin{array}{l}\text { Effective } \\
\text { Tax }\end{array}$ & $\begin{array}{l}\text { Shadow } \\
\text { Consump- } \\
\text { tion Tax }\end{array}$ & $\begin{array}{c}\text { Budget } \\
\text { Share }\end{array}$ & $\begin{array}{c}\text { Nominal } \\
\text { Revenue } \\
\text { Share }\end{array}$ \\
\hline 1 & Rice & 0 & 2.4 & -1.1 & 25.4 & 0 \\
\hline 2 & Wheat and grain & 0 & 2.1 & -0.3 & 5.1 & 0 \\
\hline 3 & Vegetables and fruits & 0 & 0.8 & 4.5 & 6.9 & 0 \\
\hline 4 & Livestock (meat) & 0.7 & 2.5 & 6.4 & 5.6 & 0.7 \\
\hline 5 & Fisheries & 0 & 4.1 & 4.5 & 7.0 & 0 \\
\hline 6 & Edible oil & 8.3 & 11.8 & 47.0 & 2.4 & 3.6 \\
\hline 7 & Sugar and gur & 35.9 & 39.0 & 39.0 & 1.2 & 7.4 \\
\hline 8 & Other food & 4.0 & 45.4 & 9.5 & 6.6 & 1.8 \\
\hline 9 & Tobacco products & 77.8 & 84.7 & 26.2 & 2.1 & 14.6 \\
\hline 10 & Clothing & 2.6 & 24.2 & 8.9 & 5.2 & 1.9 \\
\hline 11 & Manufactured goods & 11.1 & 26.5 & 29.5 & 5.9 & 59.4 \\
\hline 12 & Traditional energy & 0 & 0.7 & -0.1 & 6.5 & 0 \\
\hline 13 & Commercial energy & 7.5 & 42.5 & -36.0 & 1.9 & 9.5 \\
\hline 14 & Housing & 0 & 4.0 & 16.3 & 8.0 & 0 \\
\hline \multirow[t]{2}{*}{15} & Services & 0.1 & 6.5 & 16.2 & 10.0 & 1.1 \\
\hline & Mean/total & 3.8 & 13.5 & 13.5 & 100.0 & 100.0 \\
\hline
\end{tabular}

Table 1B. Budget Shares, Expenditure and Price Elasticities of Commodities

\begin{tabular}{lccc}
\hline No. Commodity Groups & Budget Share (\%) & Nie & Nii \\
\hline 1 Rice & 25.4 & 0.46 & -0.49 \\
2 Wheat and grain & 5.1 & 0.65 & -0.54 \\
3 Vegetables and fruits & 6.9 & 1.01 & -0.78 \\
4 Livestock (meat) & 5.6 & 1.42 & -0.96 \\
5 Fisheries & 7.0 & 1.01 & -0.78 \\
6 Edible oil & 2.4 & 0.99 & -0.77 \\
7 Sugar and gur & 1.2 & 1.17 & -0.82 \\
8 Other food & 6.6 & 1.18 & -0.89 \\
9 Tobacco products & 2.1 & 1.36 & -0.98 \\
10 Clothing & 5.2 & 0.94 & -0.70 \\
11 Manufactured goods & 5.9 & 1.42 & -0.89 \\
12 Traditional energy & 6.5 & 0.27 & -0.26 \\
13 Commercial energy & 1.9 & 1.19 & -0.85 \\
14 Housing & 8.0 & 1.80 & -1.20 \\
15 Services & 10.0 & 1.62 & -1.00 \\
\hline
\end{tabular}

Source: Hossain (1995)

Notes: shadow consumption tax indicates the divergence of market prices of goods from their shadow or international border prices.

(a) Nie: expenditure elasticity of i; (b) Nii: own price elasticity of $i$; (c) Livestock contains meat and dairy products; Gur: molasses. Traditional energy contains fuel wood and other bio-mass energy items; commercial energy contains kerosene, petrol, electricity, and gas. 


\section{Estimation of a Modified Linear Expenditure System (LES)}

For the purpose of generating the required parameters of LES, the urban and rural households have been grouped into 12 distinct groups ( 6 urban and 6 rural), differentiated on the basis of their per capita expenditure. The grouping was guided by two considerations. First, the interval of per capita expenditure that defines a group should not be so wide that it mitigates group homogeneity in allowing identification of groups below poverty line. Second, there must be a large enough number of households within each group to allow estimation of a demand system consisting of 15 commodity groups. The household expenditure survey used for the estimation contained information for about 1,500 households (500 urban and 1,000 rural) for the year 1985/86. The number of consumption items listed in the survey data was 136 ; these items were then merged into the 15 commodity groups appropriate for estimation of LES. ${ }^{10}$ The nonlinear maximum likelihood estimation of the modified LES for each of the 12 household groups was carried out by using the software SHAZAM. However, good fits were obtained for all but 2 commodity groups (the lowest of the rural expenditure groups). Perhaps the most important result was that " $b$ " (marginal budget shares) estimates were all found to be highly significant (equation 5). The " $\mathrm{t}$ " values of the parameter estimate involving "a" (constant term), however, were uneven; on average, the parameter estimates were significant in 8 of the 12 cases. The parameter estimates enable computation of the expenditure elasticities of the commodities, as well as their own price elasticities, as presented in Table 1B.

Once the parameters of the modified LES ("a" and "b") were obtained, along with the mean per capita monthly expenditure $\left(\mathrm{M}^{\mathrm{b}}\right)$ for each of the 12 urban and rural household groups, it was straightforward to calculate from equation (5) $\mathrm{E}_{01}{ }^{\mathrm{h}}$ for each group.

\section{Results: Distributional Impact of the VAT}

The results of the exercise showing the distributional impact of introducing VAT is summarized in Table 2. It presents the estimates of $\left(E_{01}{ }^{h} / M^{h}\right)$, i.e., the equivalent variations as proportions of the per capita household group expenditure in percentage terms in rural and urban areas. First, the results indicate that some groups benefit while others lose because of the introduction of uniform (proportional) VAT. Second, and more important, is the fact that the reform leads to a net loss of income for four urban and four rural groups that are relatively poor and form a large majority of the population. In particular, the loss to the groups below poverty line (the two poorest rural and urban groups, constituting about half of the population) range from 2 percent to 3.5 percent of their income. On the other hand, the reform would benefit two urban and two rural groups that are richer and form a small minority of the population. The loss to the poorer groups ranges from 1.9 percent to 3.5 percent of monthly expenditure, while the gain to the

${ }^{10}$ In addition to the expenditure data, information on household characteristics and quantity of consumption of mainly food items was also reported in the data set. 
Table 2. Equivalent Variation $\left(\mathrm{E}_{01}{ }^{\mathrm{h}}\right)$ for Uniform VAT

\begin{tabular}{|c|c|c|c|c|c|c|}
\hline Group & $\begin{array}{c}\text { PCEX } \\
\text { taka/month }\end{array}$ & $\begin{array}{l}\text { Percent- } \\
\text { age of hh }\end{array}$ & $\begin{array}{c}\text { Sample } \\
\text { Size }\end{array}$ & $\begin{array}{l}\text { Mean hh } \\
\text { Size }\end{array}$ & $\begin{array}{c}\text { Mean PCEX } \\
\left(\mathrm{M}^{\mathrm{h}}\right)\end{array}$ & $\begin{array}{c}\mathrm{EV}(\%) \\
\left(\mathrm{E}_{\mathrm{ol}}^{\mathrm{h}} / \mathrm{M}^{\mathrm{h}}\right)\end{array}$ \\
\hline
\end{tabular}

$\underline{\text { Urban }}$

$\begin{array}{rrrrrrr}1 & <249 & 1.1 & 42 & 7.2 & 210.9 & -3.5 \\ 2 & 250-349 & 2.4 & 82 & 7.1 & 304.8 & -3.3 \\ 3 & 350-449 & 2.4 & 70 & 6.5 & 401.4 & -2.2 \\ 4 & 450-599 & 2.9 & 108 & 5.9 & 523.6 & -2.8 \\ 5 & 600-699 & 1.2 & 52 & 6.2 & 641.8 & +4.9 \\ 6 & 700+ & 4.0 & 146 & 5.4 & 1092.4 & +8.1\end{array}$

$\underline{\text { Rural }}$

\begin{tabular}{rrrrrrr}
1 & $<249$ & 18.2 & 219 & 6.2 & 201.7 & -3.2 \\
2 & $250-349$ & 27.9 & 316 & 6.3 & 298.3 & -2.0 \\
3 & $350-449$ & 19.4 & 223 & 5.6 & 399.3 & -1.9 \\
4 & $450-599$ & 12.4 & 149 & 5.6 & 504.9 & -3.1 \\
5 & $600-699$ & 3.5 & 42 & 4.9 & 644.4 & +4.5 \\
6 & $700+$ & 4.7 & 51 & 5.3 & 944.7 & +6.1 \\
& & & & & 427.6 & \\
\hline
\end{tabular}

Source: Hossain (1995).

Note: PCEX: per capita expenditure (monthly) in taka; hh: household; $\mathrm{E}_{\mathrm{ol}}{ }^{\mathrm{h}}$ and $\mathrm{M}^{\mathrm{h}}$ are as defined in equation (5); EV: equivalent variation. 
richer groups ranges from 4.5 percent to 8.1 percent of monthly expenditure. In general, in rural areas the magnitudes of gain or loss are smaller but the incidence pattern is similar.

The results of the exercise, however, must be treated with caution, as many details are omitted. For example, if the VAT were to replace import tariffs, benefits to richer urban households, which consume a higher proportion of imported goods, would likely be even higher. On the other hand, the incorporation of cash and in-kind consumption (relevant in rural Bangladesh) in the analysis is likely to lead to estimates indicating lower levels of losses to poorer households, even though they would still lose. The basic result, thus, appears to be very robust; relative to the pre-reform tax regime, a uniform VAT would always benefit richer groups and adversely affect the poorer households. The framework is also useful because it enables us to assess an alternative, revenue-neutral tax reform that yields a more desirable distribution of income.

\section{E. An Alternative Reform Package}

To mitigate the adverse distributional impact of a uniform, proportional VAT applicable to all commodities, another reform package was examined. It includes a proportional VAT with exemptions on certain items to allow for "distributional" considerations; in addition, it is proposed that certain excises on luxury goods consumed by the richer segments of the population be retained at the present level. The choice of particular commodities for zero rating and the imposition of additional excises were guided by their distributional characteristics. While rigorous methods could be used to identify the distributional characteristics of the commodities, one could also look at the expenditure share of these commodities in the consumption basket of the urban and rural household groups. It is found that, in general foodgrains and vegetables, traditional energy, and, to a lesser extent, clothing make up a larger share of expenditure in the poorer household groups in rural and urban areas relative to the richer household groups. Thus the alternative tax reform package identified here maintains the revenue constant, sets a zero rate on foodgrains and vegetables, and applies a proportional VAT at an enhanced rate on the remaining commodities; in addition, the package imposes excise taxes on tobacco, energy goods, and sugar, which feature prominently in the consumption basket of richer household groups. ${ }^{11}$

The consumption of foodgrains and vegetables was roughly 23 percent of the total private consumption expenditure for $1984 / 85$. Setting the tax on the foodgrains group to zero, and with additional excises, the required rate of VAT to keep revenue constant was approximated to be 9.9 percent of expenditure on all other commodities. ${ }^{12}$

${ }^{11}$ For simplicity, the problems of administration and the payment of rebates, which would be necessary to make such a system operational, have been ignored. In a country like Bangladesh, failure to administer a system of rebates to compensate the agricultural sector for the cost of the VAT on inputs may have significant distributional consequences not addressed in this paper.

${ }^{12}$ The rate was calculated iteratively from the relationship $\mathbf{t}^{\mathrm{e}^{\prime}} . \mathbf{X}=\mathbf{r}^{\mathbf{v}^{\prime}} . \mathbf{X}=\mathrm{R}$, where $\mathrm{X}$ is the vector of aggregate purchases in the pre-reform period. The revenue-neutral VAT rate (r) was then calculated as follows. Some entries, like tobacco products and commercial energy, 
Table 3 presents the estimates of equivalent variation $\left(E_{o 1}{ }^{h} / M^{h)}\right.$ for this reform package for different urban and rural groups. Again, the pattern of results show that the impact of a selective VAT is beneficial to the rich and harms the poor. However, in this case, it is clear that the magnitudes of loss or gain are smaller than in the uniform VAT case. The poorest group in urban areas loses most - equivalent to about 2.4 percent decrease in its total expenditure. The richest group, on the other hand, benefits-equivalent to about a 6.6 percent increase in its total expenditure. In rural areas, the loss to the poorest group is -1.2 percent, while the benefit to the richest group amounts to +4.6 percent. In this case, the distribution of losses is also different in rural and urban areas. In the uniform VAT case, four of the urban groups and four of the rural groups suffer losses. In the selective VAT case, three of the rural groups suffer smaller losses, but now five urban groups lose. This could be attributable to the higher tax on nonfood items, which features prominently (with a larger budget share) in the budget of urban households. The upshot of the analysis is that a selective VAT, with some zero rating (or exemptions) coupled with some additional excises, is to be clearly preferred to the completely uniform VAT if the distributional issues are of dominant concern in the tax reform measures. The results of the study are also broadly consistent with the conclusion of a similar study on India (Ahmad and Stern (1987)), which indicated that a uniform VAT on all final goods is clearly regressive and undesirable. The same study, however, also shows that a uniform VAT with exemptions or zero rates on certain items to allow for "distributional considerations" is much less regressive than the proportional VAT. ${ }^{13}$ The study (Hossain, 1995), presented above does not examine the effects of setting a relatively high VAT threshold (implying exemption of small business and activities from the VAT) as an alternative to high excises. Such a high threshold may increase the progressivity of the VAT and may be easier to administer, even though it may erode the tax base somewhat.

were constrained to be the same as in $\mathbf{t}^{\mathrm{e}}$. Foodgrains were assumed to be zero rated, and all other taxes were replaced by a uniform rate in the manner defined above.

${ }^{13}$ It must be noted that exemption of a commodity from VAT (which implies no credit given for purchase of inputs) is not the same as zero rating of the commodity (with credit given for input purchase). Owing to modeling difficulties, in the reform package, the agricultural goods are set to be zero rated; however, since subsidy from major agricultural inputs were withdrawn and markets liberalized during mid 1980 's, it is reasonable to assume that distributive impact of exemption will not be significantly different from zero rating. 
Table 3. Equivalent Variation $\left(\mathrm{E}_{\mathrm{ol}}{ }^{\mathrm{h}}\right)$ for Uniform VAT with Zero-Rated Commodities and Excise Taxes

Group PCEX Percent- Sample Mean hh Mean PCEX E.V.(\%) $\begin{array}{lllll}\text { taka/month age of hh } & \text { Size } & \text { Size } & \left(M^{\mathrm{h}}\right) & \left.\mathrm{E}_{01}{ }^{\mathrm{h}} / \mathrm{M}^{\mathrm{h}}\right)\end{array}$

\section{Urban}

$\begin{array}{rrrrrrr}1 & <249 & 1.1 & 42 & 7.2 & 210.9 & -2.4 \\ 2 & 250-349 & 2.4 & 82 & 7.1 & 304.8 & -2.7 \\ 3 & 350-449 & 2.4 & 70 & 6.5 & 401.4 & -1.2 \\ 4 & 450-599 & 2.9 & 108 & 5.9 & 523.6 & -2.0 \\ 5 & 600-699 & 1.2 & 52 & 6.2 & 641.8 & -0.3 \\ 6 & 700+ & 4.0 & 146 & 5.3 & 1092.4 & +6.6\end{array}$

\section{$\underline{\text { Rural }}$}

\begin{tabular}{rrrrrrr}
1 & $<249$ & 18.2 & 219 & 6.2 & 201.7 & -1.2 \\
2 & $250-349$ & 27.9 & 316 & 6.3 & 298.3 & -1.9 \\
3 & $350-449$ & 19.4 & 223 & 5.6 & 399.3 & -1.1 \\
4 & $450-599$ & 12.4 & 149 & 5.6 & 504.9 & +0.1 \\
5 & $600-699$ & 3.5 & 42 & 4.9 & 644.4 & +0.8 \\
6 & $700+$ & 4.7 & 51 & 5.3 & 944.7 & +4.6 \\
& & & & & & \\
\hline
\end{tabular}

Source: Hossain (1995).

Note: PCEX: per capita expenditure (monthly) in taka; hh: household; $\mathrm{E}_{\mathrm{ol}}{ }^{\mathrm{h}}$ and $\mathrm{M}^{\mathrm{h}}$ are as defined in equation (5); EV: equivalent variation. 


\section{Conclusion}

The paper shows how a quantitative framework based on an equivalent variation measure that incorporated demand response of a price change can be utilized to assess the impact of discrete policy changes on different household groups in the economy. It is a relatively simple framework, and the data requirements are reasonable. Household survey data are now available for a wide range of countries, and the framework utilizes the richness of the data to assess the poverty and social impact of policy reforms.

The findings of our study suggest that, among the different possible VAT schemes, a selective VAT scheme with some exemptions (or zero rating) and additional excises is likely to be more acceptable to the general public and policymakers. ${ }^{14}$ We have also studied other interesting cases of selective VAT with a different combination of taxes, but the reform package discussed above seems to be the most feasible because it is revenue neutral in its impact and looks relatively attractive to policymakers in terms of distributional features. However, it must be noted that, although the nonuniform VAT has clear advantages over a uniform VAT with regard to distributional considerations, a nonuniform VAT scheme with more than a few categories may create administrative difficulties. ${ }^{15}$ In particular, authorities in even highly advanced European tax systems find it very difficult to administer the rebate system that goes with the zero rating of agricultural goods. In the context of Bangladesh, if the agricultural goods (foodgrains and vegetables) were exempted from the VAT (instead of being zero rated) because of administrative difficulties, this would introduce an additional degree of distributional inequity, adversely affecting the rural households and causing more of these goods to be consumed. It is clear from the presentation that the study avoided estimation of an explicit social welfare function, which requires assigning different weights to different household groups. Instead, it focused on distributional impacts of reforms on household groups because it is considered to be more appealing to the policymakers. ${ }^{16}$

The analysis presented above is merely suggestive. It is based on detailed household expenditure survey data, and various households were classified only in terms of per capita expenditure. The data in their present form do not distinguish between purchases from market and consumption from household's own production, a phenomenon that is likely to be important in rural Bangladesh, particularly among owner-occupied farms. Also, many transactions in rural and urban areas do not go through formal markets. Thus, an incidence

${ }^{14}$ The VAT scheme introduced in 1991 imposes a uniform VAT with exemptions for agricultural goods and most services coupled with a zero rating for exports and the retention of excise taxes on tobacco products, petroleum products, and gas.

${ }^{15}$ Tait (1991) provides a detailed and systematic discussion of the administrative problems and issues relating to the introduction of a VAT.

${ }^{16}$ In the original paper (Hossain, 1995), however, the distributional characteristics of different commodities were estimated based on alternative inequality aversion parameters or social welfare weights for different household groups. 
analysis based on an equivalent variation measure is likely to overstate the magnitude of losses or gains to such households. Households with their own farms are likely to be better off, however, than the households that rely primarily on wage income and form part of the growing number of landless laborers.

One crucial formulation underlying the model is that commodity taxes are fully passed through to consumer prices. It is likely that the results are affected by the assumptions of the pricing rule. For some commodity groups, as an alternative to full forward shifting, one can assume full backward shifting, in which domestic prices are determined by world prices, so that taxes are passed back, thereby compressing factor returns in the taxed sectors. Analytically, Dahl and Mitra (1991) have shown that the revenue effect and welfare cost also depend on the particular variant (or mix) of the pricing rule assumed. As noted earlier, Stern (1987b) has studied the effect of taxes in noncompetitive models. He concludes that 100 percent tax shifting, as assumed in the conventional model, is a reasonable intermediate case that is valid for a wide range of market conditions, and not an extreme or polar case, as is often implied. 


\section{Simple Analytics of the Indirect Utility Function and the Expenditure Function}

The indirect utility function (V) is defined as the maximum utility (U) achievable at given set of prices and income. It is represented as:

$$
V(q, M)=\operatorname{Max} . U(X) \text {, subject to } q \cdot X=M \text {, }
$$

where $\mathrm{q}$ is the vector of consumer prices, $X$ is the vector of quantities of goods consumed, and $\mathrm{M}$ is the income of consumer/household.

The properties of indirect utility function are as follows:

$\mathrm{V}(\mathrm{q}, \mathrm{M})$ is decreasing in $\mathrm{q}$, i.e., $\mathrm{V}^{\prime}(\mathrm{q}) \leq 0$, and

$\mathrm{V}(\mathrm{q}, \mathrm{M})$ is increasing in $\mathrm{Y}$, i.e., $\mathrm{V}^{\prime}(\mathrm{M}) \geq 0$.

Since V $(q, M)$ is strictly increasing in $M$, the

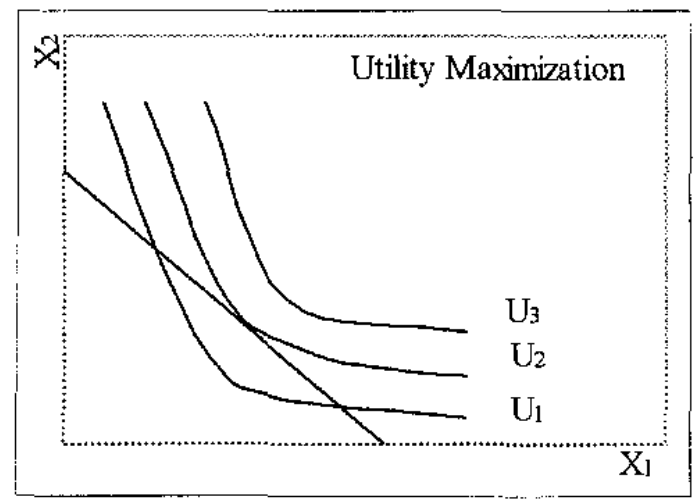
function can be inverted to solve for $\mathrm{M}$ as a function of $\mathrm{U}$. It is the function that relates income (M), or total expenditure (e), and utility, and it is called the expenditure function:

$$
\text { e }(q, U)=\text { Minimize } q . X \text {, subject to } U(X) \geq U \text {. }
$$

The expenditure function gives the minimum cost of achieving a fixed level of utility.
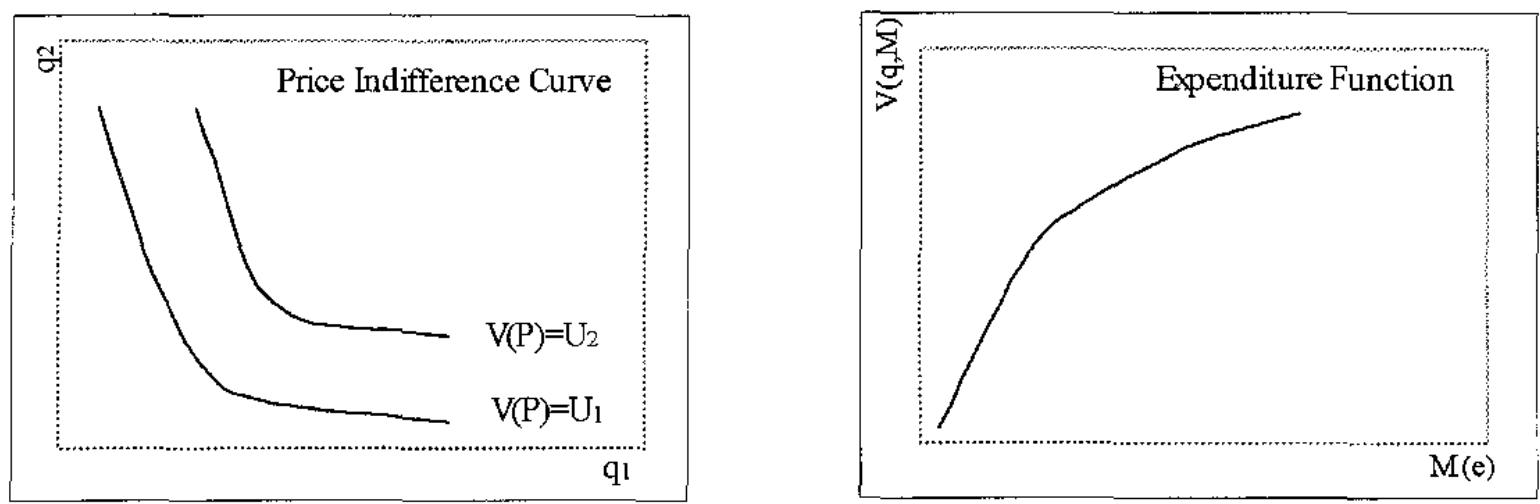


\section{References}

Ahmad, Ehtisham, and Nicholas H. Stern, 1987, "Alternative Sources of Government Revenue: Illustrations from India, 1979-80," in The Theory of Taxation for Developing Countries, ed. by David Newbery and Nicholas H. Stern (Oxford: Oxford University Press for the World Bank).

Bell, Clive, and T. N. Srinivasan, 1984, "On the Uses and Abuses of Economy wide Models in Development Policy," in Economic Structure and Performance, ed. by Moshe Syrquin, Lance Taylor, and Larry Westphal (Orlando, Florida: Academic Press).

Bourguignon, Francois, and Luiz Pereira da Silva, 2002, "Evaluating the Distributional and Poverty Effects of Macro Policies, a Compendium of Existing Techniques: Introducing Linkages Between Macro and Micro Techniques," Part I - Introduction in World Bank PSIA Tool Kit - Part I - Introduction, available in the Internet: www worldbank,org/poverty/psia

Dahl, Henrik, and Pradeep Mitra, 1991,"Applying Tax Models in Country Economic Work: Bangladesh, China, and India,"World Bank Economic Review, Vol. 5 (September) pp. 553-72.

Devarajan, Shantayanan, and Delfin S. Go, 2002, "A Macroeconomic Framework for Poverty Reduction Strategy Papers, With an Application to Zambia," World Bank Africa Region Working Paper Series No. 38 (Washington, World Bank).

Dervis, Kemal, Jaime De Melo, and Sherman Robinson, 1982, General Equilibrium Models for Development Policy (Cambridge: Cambridge University Press for the World Bank).

Hossain, Shahabuddin, 1995, "The Equity Impact of the Value-Added Tax in Bangladesh, Staff Papers, International Monetary Fund, Vol. 42 (June), pp. 411-32.

Inchauste, Gabriela, 2002, "Poverty and Social Impact Analysis in PRGF-Supported Programs," IMF Policy Discussion Paper 02/11 (Washington: International Monetary Fund).

Kende-Robb, Caroline, 2003, "Poverty and Social Analysis-Linking Macroeconomic Policies to Poverty Outcomes: Summary of Early Experiences," IMF Working Paper 03/43 (Washington: International Monetary Fund).

King, Mervyn A. 1983, "Welfare Analysis of Tax Reform Using Household Data," Journal of Public Economics, Vol. 21 (July), pp. 183-214. 
Newbery, David, and Nicholas H. Stern, 1987, The Theory and Practice of Tax Reform in Developing Countries (Oxford: Oxford University Press).

Shoven, John B., and John Whalley, 1984, "Applied General Equilibrium Models of Taxation and International Trade: An Introduction and Survey," Journal of Economic Literature, Vol. 22 (September), pp. 1007-151.

Stern, Nicholas H., 1987a, "The Theory of Optimal Commodity and Income Taxation," in The Theory of Taxation for Developing Countries, ed. by David Newbery and Nicholas H. Stern (Oxford: Oxford University Press for the World Bank).

_ 1987b, "Aspects of the General Theory of Tax Reform," in The Theory of Taxation for Developing Countries, ed. by David Newbery and Nicholas H. Stern (Oxford: Oxford University Press for the World Bank).

Tait, Alan, 1991, Value Added Tax: Administrative and Policy Issues, IMF Occasional Paper No. 88 (Washington: International Monetary Fund). 